\title{
Research on Coupling Coordination Evaluation of Rail Transit and Urban Development
}

\author{
Yangxi Huang ${ }^{1, *}$ \\ ${ }^{1}$ School of Public Administration and Law, Southwest Jiaotong University, Chengdu, Sichuan 610031, China \\ *Corresponding author. Email: 3067683277@qq.com
}

\begin{abstract}
In recent years, in order to alleviate traffic congestion, many cities blindly build rail transit regardless of their own development level, resulting in serious financial liabilities, land acquisition and other problems. It is of positive significance to scientifically evaluate the coordinated relationship between rail transit and urban development, and timely adjust the relationship between the two to promote the coordinated development of the system. Based on the connotation of the coordinated development of urban rail transit and the theory of system synergy, this paper constructs the evaluation index system and coupling coordination model of urban rail transit and urban development by using entropy method, and evaluates the coupling coordination status of the two. Taking Shanghai as an example, this paper demonstrates the dynamic change of coupling coordination degree between rail transit and urban development in Shanghai from 2009 to 2019, and puts forward some suggestions to promote the coordinated development of the two.
\end{abstract}

Keywords: Rail transit, Urban development, Coupling coordination, Entropy weight method.

\section{INTRODUCTION}

In recent years, many cities have started to build rail transit to ease traffic congestion, but due to the lack of a good grasp of their own strength and actual demand, there are problems such as over-advance planning, over-concentration of construction scale and lack of funds, not only to a certain extent to increase the burden on the government, but also affected the healthy development of the city. Rail Transit System and urban development system are mutually conditioned and restricted, and there are obvious differences in feedback mechanism and operation rules In addition, the construction of Rail Transit in China started when the urban population and space developed to a certain scale, so there must be some contradictions between the two in the operation process, such as the expropriation of urban land during the construction of Rail Transit, in the operation process needs the government massive financial subsidy and so on to be able to affect its and the city coordinated development. The coupling and coordinated development of rail transit and cities means the harmonious unity of Rail Transit Construction with urban social progress, economic growth and environmental improvement, the essence of connotation lies in seeking the best combination and structure of Rail Transit Construction and urban development, that is to say, it is very important to allocate all kinds of resources in time so as to make the construction of rail transit more orderly and finally achieve harmony and optimization with the overall development of the city.

In the study of the coupling coordination of Urban Development, scholars focus on the following aspects: First, the coupling coordination of urban development and other industrial development. Infrastructure and the provision of public services are considered to be the main factors limiting the growth of urban boundaries[1]. On the question of how to coordinate urban development with tourism, scholars have studied different provinces and cities, on the basis of constructing the evaluation index system of their compatibility, the quantitative evaluation is made by using the model method[2], [3], [4], [5]. The second is the coupling and coordination relationship between urban development and regional traffic. From the point of view of urban agglomeration[6], [7] and horizontal contrast ${ }^{[8]}$, the authors make a comprehensive evaluation and prediction of the coupling coordination degree between urban and regional traffic. Third, the coupling and coordination 
relationship between urban development and land use. Based on the background of ecological civilization, this paper analyzes the coupling and harmonious distribution characteristics and driving forces of urban construction and land intensive use[9]. Generally speaking, the research on urban development and land intensive use mainly focuses on the coordination of land price and urbanization, while the research scale involves counties, cities and provinces[10], [11], [12].

According to the research at home and abroad, there are few researches on the coupling and coordination relationship between Rail Transit and urban development. Based on data envelopment analysis (DEA) model, Guo Jianmin and others constructed the evaluation index of Rail Transit and urban economic and social development ${ }^{[13]}$. By analyzing the relationship between Rail Transit and urban development, Zhang Xiaodong puts forward the concrete strategy of Coordinating Rail Transit and urban development from five aspects ${ }^{[14]}$. However, few scholars start from the large-scale system composed of rail transit and urban development, and study the coupling situation between the two systems based on the coupling coordination model. On the basis of summarizing the previous research experience, this paper uses quantitative method to analyze the coupling and coordination relationship between Rail Transit and urban development. In this paper, the data of Shanghai in 2009-2019 are selected as the research sample, and the coupling coordination degree is investigated based on the time dimension, which fully reflects the dynamic characteristics of the two. The research results can further enrich the theory and evaluation method system of Rail Transit and urban development research, and provide good experience and reference for the government to promote the rail transit planning and construction project from the macro-level.

\section{INDEX SYSTEM AND RESEARCH METHOD}

\subsection{Construction of Index System}

Urban Development will affect the construction scale and operation efficiency of Rail Transit, and the development of rail transit will also affect the economic, social benefits and spatial form of urban development. As the Rail Transit System and Urban Development System are dynamic and complex systems, it is necessary to select indicators to represent their comprehensive development level according to the actual situation of each system.
Based on the principles of Scientificity, systematicness, comparability, availability and measurability, this paper makes reference to the selection methods of the indexes of Guo Jianmin ${ }^{[13]}$, Feng Guoqiang[15], etc. , combined with the connotation of coordinated development of rail transit and city, the evaluation index system of the two systems is constructed. Some indexes need to be calculated, if the passenger volume ratio of rail transit is the ratio between the passenger volume of rail transit and the passenger volume of urban public transport, the proportion of the built-up area is the ratio of the area of the built-up area to the total area of the city, as shown in "Table 1". 
Table 1. Evaluation index system of Rail Transit and urban development

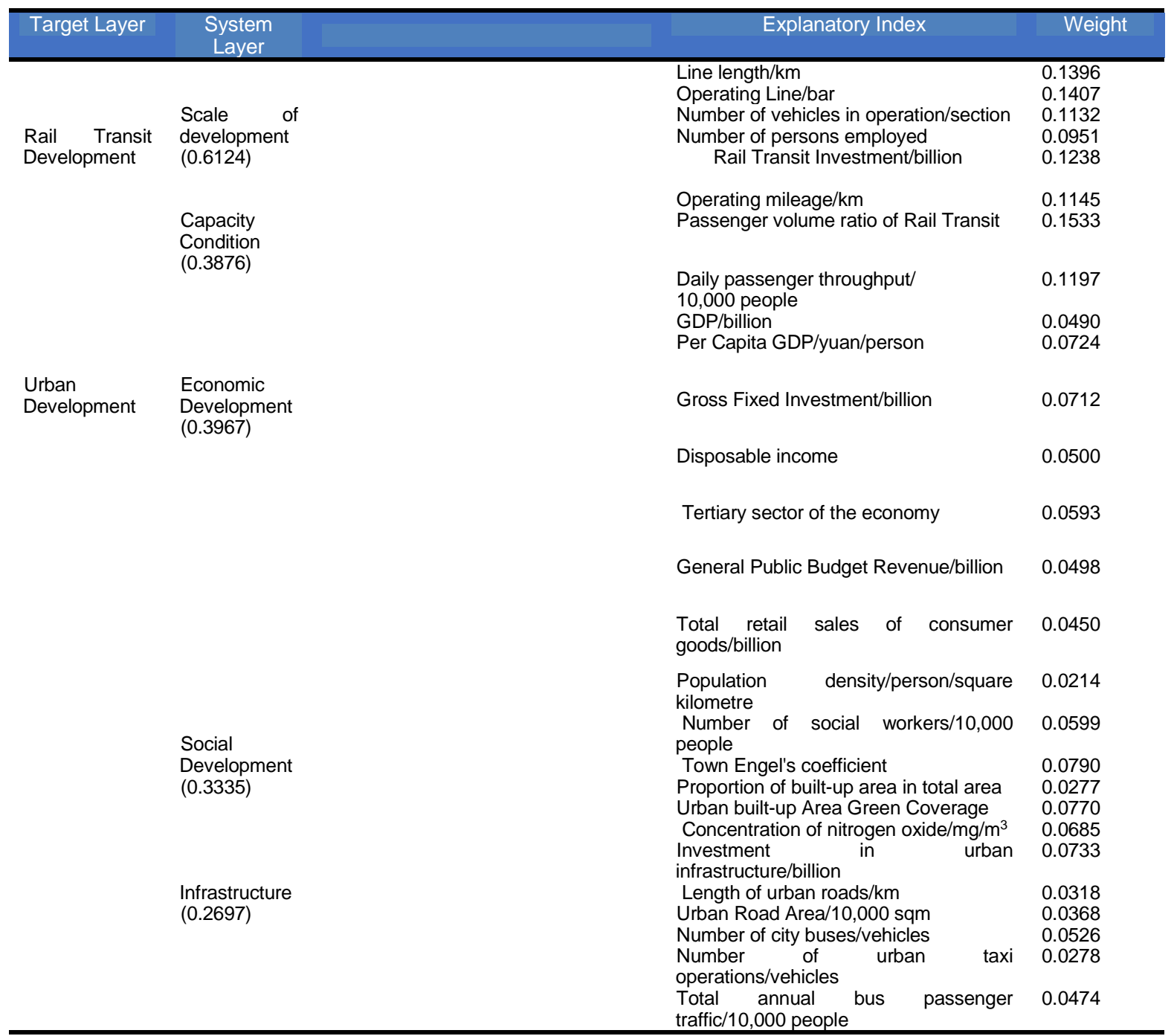

\subsection{Source and Processing of Indicator Data}

This paper analyzes the data of Shanghai from 2009 to 2019, the related index data mainly comes from the corresponding year "Shanghai Statistical Yearbook", "China Urban Construction Statistical Yearbook" , Shanghai Annual Statistical Bulletin, Urban Rail Transit Statistics and analysis reports.

For the comprehensive level index of Rail Transit and urban development, the entropy method is used in this

paper, $x_{i j}(i=1,2, \ldots n ; j=1,2, \ldots m) \quad$ Represents the statistical value of indicator $\mathrm{j}$ in System i. First, we standardized the raw data of the indicator, $p_{i j}$ is the normalized dimensionless value:

$$
\begin{aligned}
& p_{i j}=x_{i j} / \sum_{i=1}^{n} x_{i j} \\
& \varepsilon_{\mathrm{j}}=-k \sum_{i=1}^{n} p_{i j} \ln \left(p_{i j}\right) \\
& w_{i j}=\left(1-\varepsilon_{j}\right) / \sum_{j=1}^{m}\left(1-\varepsilon_{j}\right)
\end{aligned}
$$

The entropy method is calculated as follows:

Then the comprehensive level value of any period in the corresponding system can be obtained $u_{i j}$

$u_{i}=\sum_{j=1}^{m} w_{j} \times p_{i j,}(i=1,2, \ldots n)$ 


\subsection{Construct of Evaluation Model}

The term coupling, which is derived from the concept of physics, focuses on reflecting the degree of correlation among the internal elements of each subsystem, and represents the trend of the coordinated development of the system from disorder to order. Based on the concept of capacity coupling in physics, the coupling coordination model of Rail Transit and urban development is constructed. The coupling coordination degree calculated can not only reflect the correlation degree of each subsystem in the development process, it can also reflect the development level of the whole system synergy effect. The coupling coordination degree of Rail Transit and urban development refers to the quantitative research on the coordination development of society, Economy and Environment Between Rail Transit and urban development under certain resource constraints. The $u_{1} 、 u_{2}$ coordination degree evaluation model which measures the static system distance to reflect the overall synergy effect is as follows:

$C=\left[\frac{u_{1} \times u_{2}}{\left(\frac{u_{1}+u_{2}}{2}\right)^{2}}\right]^{K}$

In the above equation, $\mathrm{C}$ is the Coordination Degree and $\mathrm{K}$ is the adjustment coefficient. Considering the two systems of Rail Transit and urban development involved in this paper, $\mathrm{K}=2$. Coordination Degree $\mathrm{C}$ can effectively evaluate the overall coordination degree between the Rail Transit System and the urban development system, but it is difficult to estimate the respective development status within the two systems, that is, we cannot determine whether the two systems are in high-level coordinated development or low-level coordinated development. Therefore, it is necessary to introduce

Table 2. Evaluation criteria of coupling coordination degree between Rail Transit and urban development

\begin{tabular}{lll}
\hline Coupling Coordination Class & Coupling coordination interval & \multicolumn{1}{c}{ Coupling coordination level } \\
\hline Maladjusted recession type & $0<\mathrm{D}<0.1$ & Extreme dissonance \\
& $0.1 \leq \mathrm{D}<0.2$ & highly dysfunctional \\
& $0.2 \leq \mathrm{D}<0.3$ & Moderate dissonance \\
& $0.3 \leq \mathrm{D}<0.4$ & Mild disorder \\
Transitional Development & $0.4 \leq \mathrm{D}<0.5$ & Borderline dysfunctional \\
& $0.5 \leq \mathrm{D}<0.6$ & Grudgingly coordination \\
& $0.6 \leq \mathrm{D}<0.7$ & Primary Coordination \\
Coordinated Development & $0.7 \leq \mathrm{D}<0.8$ & Moderate coordination \\
& $0.8 \leq \mathrm{D}<0.9$ & Good Coordination \\
& $0.9 \leq \mathrm{D}<1$ & Highly coordinated \\
\hline
\end{tabular}

the coupling coordination model (also known as the deviation coefficient minimization coordination model) to Quantitative analysis the level of their coordinated development. The index can avoid the abnormal situation that the rail transit and urban development level is low but the coordination degree is high. It can also reflect the overall characteristics of the integrated system. Compared with the coordination degree model, the index has higher universality and stability, it can be used for quantitative evaluation and comparison of the coordinated development of rail transit and city in the same region in different periods. Based on the related research results, the coordination model is modified as follows:

$$
\begin{aligned}
& D=\sqrt{C \times T} \\
& T=\alpha \times u_{1}+\beta \times u_{2}
\end{aligned}
$$

Where $\mathrm{D}$ is the coupling coordination degree and $t$ is the comprehensive level index of Rail Transit and urban development, which reflects the overall level of the two systems, $\alpha 、 \beta$ is the undetermined weight of the subsystem, In the process of coordinated development between Rail Transit and city, urban development is influenced by other factors, although rail transit is the main supporting system, therefore, the undetermined weights of contribution degree of Rail Transit System and urban development system are 0.4 and 0.6 respectively.

The range of $\mathrm{D}$ is $[0,1]$. On the basis of the literature of Yang Li[16], this paper divides the evaluation criteria of the coupling and coordination degree between Rail Transit and urban development as shown in "Table 2". Specifically, if $\mathrm{u}_{1}>\mathrm{u}_{2}$, then the coupling type is the lagging type of urban development; if $\mathrm{u}_{1}<\mathrm{u}_{2}$, then the coupling type is the lagging type of Rail Transit; if $\mathrm{u}_{1}=\mathrm{u}_{2}$, then the coupling type is the synchronous type of Rail Transit and urban development. 


\section{AN EMPIRICAL ANALYSIS ON THE COUPLING DEGREE OF SHANGHAI METRO AND URBAN DEVELOPMENT}

Table 3. Degree of coupling and coordination between Rail Transit and urban development in Shanghai from 2009 to 2019

\begin{tabular}{|c|c|c|c|c|c|c|}
\hline Year & $\begin{array}{c}\text { Comprehensive } \\
\text { Evaluation } \\
\text { Index of Rail } \\
\text { Transit- } \mathrm{u}_{1}\end{array}$ & $\begin{array}{l}\text { Comprehensive } \\
\text { Evaluation Index } \\
\text { of Urban } \\
\text { Development- } \mathrm{U}_{2}\end{array}$ & $\begin{array}{l}\text { Coordination } \\
\text { degree of dual } \\
\text { system-C }\end{array}$ & $\begin{array}{l}\text { Coupling } \\
\text { Coordination } \\
\text { Index-D }\end{array}$ & $\mathrm{u}_{1}-\mathrm{u}_{2}$ & $\begin{array}{l}\text { Type of coupling coordination } \\
\text { degree }\end{array}$ \\
\hline 2009 & 0.1067 & 0.2881 & 0.6222 & 0.3662 & -0.1814 & $\begin{array}{l}\text { Delay type of rail transit with } \\
\text { slight maladjustment }\end{array}$ \\
\hline 2010 & 0.2944 & 0.3102 & 0.9986 & 0.5509 & -0.0158 & $\begin{array}{l}\text { Lagging type of primary } \\
\text { Coordinated Rail Transit }\end{array}$ \\
\hline 2011 & 0.2816 & 0.3379 & 0.9836 & 0.5570 & -0.0563 & $\begin{array}{l}\text { Lagging type of primary } \\
\text { Coordinated Rail Transit }\end{array}$ \\
\hline 2012 & 0.3149 & 0.3544 & 0.9931 & 0.5799 & -0.0395 & $\begin{array}{l}\text { Lagging type of primary } \\
\text { Coordinated Rail Transit }\end{array}$ \\
\hline 2013 & 0.4101 & 0.3993 & 0.9996 & 0.6352 & 0.0108 & $\begin{array}{l}\text { Mild coordinated urban } \\
\text { development lag type }\end{array}$ \\
\hline 2014 & 0.5176 & 0.4598 & 0.9930 & 0.6925 & 0.0578 & $\begin{array}{l}\text { Mild coordinated } \\
\text { development lag type }\end{array}$ \\
\hline 2015 & 0.6059 & 0.4888 & 0.9772 & 0.7235 & 0.1171 & $\begin{array}{l}\text { Moderate coordinated } \\
\text { development lag type }\end{array}$ \\
\hline 2016 & 0.6701 & 0.5347 & 0.9749 & 0.7577 & 0.1354 & $\begin{array}{l}\text { Moderate coordinated } \\
\text { development lag type }\end{array}$ \\
\hline 2017 & 0.7672 & 0.6247 & 0.9792 & 0.8170 & 0.1425 & $\begin{array}{l}\text { Well-coordinated } \\
\text { development lag type }\end{array}$ \\
\hline 2018 & 0.8744 & 0.6615 & 0.9619 & 0.8475 & 0.2129 & $\begin{array}{ll}\text { Well-coordinated } & \text { urban } \\
\text { development lag type } & \end{array}$ \\
\hline 2019 & 0.9538 & 0.7584 & 0.9741 & 0.9027 & 0.1954 & $\begin{array}{l}\text { The lag type of highly } \\
\text { coordinated urban development }\end{array}$ \\
\hline
\end{tabular}

According to "Table 3", the degree of coupling coordination between Rail Transit and urban development shows that the coupling coordination between Shanghai Metro and urban development has been on the rise since 2009. In 2009, the index of the coupling coordination degree between Shanghai Metro and urban development was only 0.3662 , but in 2019, the index has reached 0.9027 , which shows that the comprehensive index of the coupling coordination degree between the two has been improved in the past 10 years. From their respective development degree, the value of $\mathrm{u}_{1}$ in 2009 was 0.1067 , the development is relatively backward, while the value of $u_{1}$ in 2010 was 0.2944 , the increase of nearly three times. In 2011, the Rail Transit Composite Index decreased compared with the previous year, the other years of the Rail Transit Composite Index was increasing year by year. The reason for this is that in 2010 Shanghai will host the World Expo, while Rail Transit is classified as the main mode of public transport travel during the expo. Thus, in 2010, the Shanghai Metro saw a leap in infrastructure construction, with average daily passenger traffic increasing by 1.5 times compared to the previous year, and Shanghai Metro Mileage nearly doubling throughout the fifteen period, the
The comprehensive evaluation index of Shanghai Rail Transit System and Urban Development System from 2009 to 2019 and the degree of their coupling and coordination are shown in "Table 3 ". 
seen in the $\mathrm{C}$ value of the degree of coordination. According to the $\mathrm{u}_{1}-\mathrm{u}_{2}$ value, the type of coupling and coordination between Rail Transit and urban development was reversed in 2012, and it was the type of lagging development before 2012, and then it was the type of lagging urban development, this suggests that Shanghai Metro's post 2012 growth is clearly superior to that of the cities. As is known to all, the construction of the Shanghai subway was the earliest in the country. At present, the city has been built on a scale that is also in the forefront of the country, but in recent years its mileage under construction is relatively small, indicating that the construction heat has passed, the existing scale of rail transit construction has been able to meet the daily needs of urban residents to support the development of urban construction. According to Shanghai Rail Transit Construction Planning from 2016 to 2020, most of the current rail transit projects are feeder lines or urban fast rail lines, which further confirms the results of the paper.

\section{CONCLUSION}

The coupling coordination model can effectively quantify the coupling coordination degree between Rail Transit System and urban development system. According to the above research, Rail Transit and urban development are interrelated, the so-called coordinated development is a dynamic concept. It does not require the continuous construction of Rail Transit, but requires constant adjustment of the inner and outer parts of the Rail Transit System so that it can develop in an orderly manner, at the same time, Rail Transit should also promote urban development in the functional process, so that the city's economic and social benefits to achieve a high degree of unity. Specific conclusions drawn from the empirical analysis are as follows:

- On the whole, the coupling degree of Shanghai Metro and Urban Development Increases Year by year, which indicates that the interaction of coupling factors in the system will be strengthened after a certain period of system development. In 2009, the two were slightly out of Kilter, as Shanghai Metro construction lagged behind urban development. With the opening of Expo 2010, the Shanghai Metro doubled during the 11th five-year plan, and the approval of urban rail projects resumed in 2018, setting off a new subway construction boom. In 2019, the degree of coordination between the two has reached 0.9027, which shows that the Shanghai municipal government is correct in guiding the relationship between
Rail Transit and urban development, at the same time, it also demonstrates the rationality and feasibility of the evaluation index system and coupling coordination model.

- From the point of view of coupling and coordination, the relationship between Shanghai Metro and urban development has gone through the process from urban development priority to rail transit lag, then rail transit priority to Urban Development Lag; In the past ten years, the two types changed from maladjustment and decline to transitional development, and then to coordinated development. It is not difficult to find that the coupling and coordination between the Rail Transit System and the urban development system is a process from small to large, from disorder to order, its goal value, scale mechanism and so on must serve the entire city economy society and the environmental development need, then realizes itself from the low level to the high level, from disorderly to the orderly evolution development.

Combined with the empirical analysis, this paper puts forward the following countermeasures and suggestions to promote the coupling and coordination between Rail Transit System and Urban Development System:

- We will increase the coverage of rail transit stations and strengthen linkage with other modes of public transport. The scale of Rail Transit Development is the basis for ensuring its achievement of the set goals. When the coverage rate of rail transit is comprehensive enough, the scale effect of Rail Transit Network will be formed, and people will be more willing to choose rail transit for travel, and the passenger flow is the main factor for rail transit to exert its traffic function and externality effect. As an important part of urban public transport, Rail Transit can be combined with other public transport modes to form a regional largescale public transport transfer hub, thus realizing the integration of Urban Rail Transit and conventional public transport, and improve the quality of rail transport services, so as to further enhance the passenger flow of rail transport.

- It is necessary to implement the concept of TOD development and do well the integration construction of railway station and city. In the planning stage of Rail Transit Network, TOD concept should be integrated, that is, the full coupling of rail transit 
network with the land distribution and comprehensive planning along the line should be paid attention to, and the integrated development and integration of rail transit hub stations and the surrounding urban blocks should be done well. Building a new urban space form, the scattered space into a compact composite space structure, and then improve the site around the use of land efficiency and urban operation rate. At the same time, the layout of the industries around the station is planned as a whole, and the city spaces with their own characteristics are connected in series through rail transit, so as to stimulate the effect of "people staying for business" and further promote the passenger flow increment of rail transit into the economic increment of the city, in order to promote the long-term quality coordinated development between the Rail Transit and the city.

\section{AUTHORS' CONTRIBUTIONS} Huang.

This paper is independently completed by Yangxi

\section{REFERENCES}

[1] Thomas D.Urban Growth Patterns and Effectiveness of the Metropolitan Urban Service Areas in Woodbury, Minnesota[J]. 2013.

[2] Jansen-Verbeke M.Leisure.Recreation and Tourism in Inner Cities:Explorative Case Studies[J].Netherlands Geographical Studies, 1985, (58) .

[3] Gao Lehua, Zhang Guanghai. Study on Coupling Development Mechanism of urbanization and tourism industry cluster Taking Shandong Province as an example [J]. Kunming: Tourism Research (quarterly), 2011, $3,(4)$.

[4] Luo Wenbin, Tan Rong. Quantitative evaluation of the coordinated relationship between urban tourism and urban development: a case study of Hangzhou [J]. Beijing: a geographical study: 2012, 31, (6) .

[5] Zhang Guanghai, Feng Yingmei. Analysis on the spatial and temporal characteristics of the degree of coupling and coordinated development between the level of tourism industrial structure and the level of urban development-Taking Shandong Province as an example $[\mathrm{J}]$. Economic management, 2013,35(05):128-138

[6] Li Shuifu. Research on coupling coordination degree of transportation and economic development from the perspective of urban agglomeration [D]. Chang'an University, 2017.

[7] Wu Chao Nan. Research on the coupling of transportation and regional economy in Beijing Tianjin Hebei [D]. Beijing Jiaotong University, 2017

[8] Meng Deyou, Lu Yuqi, fan Xinsheng, Shi Benlin. Evaluation of county traffic and economic coordination in Henan Province Based on projection pursuit model [J]. Geography research, 2013,32(11):2092-2106.

[9] Liang Liying, Liang Yanqing, Huang Zhiying, Shi Siqi. Study on the coupling coordination relationship between healthy urban development and land intensive use under the background of Ecological Civilization — Taking Beijing Tianjin Hebei as an example [J]. Ecological economy, 2020,36(04):88-94.

[10] Zhang Leqin, Chen Suping, Chen Baoping, et al. Measurement of coupling coordination degree between urbanization and land intensive use: a case study of Anhui Province [J]. Urban problems, 2014(2):75-82.

[11] Yang Huixia, Ge Jingfeng. Study on the relationship between land price and urban land intensive use under different intensive gradients [J]. Resources and environment in arid areas, 2015(8):33-38.

[12] Fan Jianshuang, Zhou Lin, Yu Xiaofen. The relationship between industrial structure evolution, urbanization quality and land intensive use and its spatiotemporal evolution characteristics $[\mathrm{J}]$. Regional research and development, 2018(4):19-24.

[13] Guo Jianmin, Han Linfei, Ma Lili. Study on urban rail transit construction level based on principal component analysis from DEA perspective $[\mathrm{J}]$. Journal of Beijing Jiaotong University, 2015,39(01):90-94.

[14] Zhang Xiaodong. Thoughts and suggestions on coordinated development of Beijing Rail Transit and city [J]. Urban planning, 2016,40(10):8185 . 
[15] Feng Guoqiang, Li Jing. Population size and urban rail transit congestion control effect [J]. Urban problems, 2020(02):49-57.

[16] Yang Li, Huang Tao Zhen. Study on the mechanism and relationship between ecological civilization and new urbanization based on coupling coordination degree model $[\mathrm{J}]$. Ecological economy, 2019,35(12):60-66. 